\title{
Experimental and numerical analyses of the dynamic failure processes of symmetric Taylor impact specimens
}

\author{
Hervé Couque ${ }^{1, *}$ \\ Nexter Munitions, 7 route de Guerry, 18023 Bourges, France
}

\begin{abstract}
Failure processes encountered in the Taylor impact specimen are of two kinds, Mode II cracks initiating within adiabatic shear bands and tensile cracks. Because friction occurring with the single Taylor configuration influences the failure processes, it is necessary to use the symmetric loading procedure providing frictionless interfaces. Numerical simulations of the symmetric Taylor test have been conducted to reproduce the failure processes observed with a highly ductile nickel and a high strength tungsten alloy. Because the adiabatic shear failure process is occurring along a three dimension path, the 3D module of the hydrocode AUTODYN was used.
\end{abstract}

\section{Introduction}

The impact test developed by Taylor [1] originally involved a long cylindrical specimen against a rigid target. From the dimensions of the deformed specimen, Taylor provides an estimate of the dynamic yield strength. Since, it has been mostly used to validate constitutive models at strain rate ranging from $10^{3}$ to $10^{4}$ $\mathrm{s}^{-1}$, and to evaluate dynamic failure properties of materials [2-4]. Two kinds of failure processes have been observed with the Taylor specimens.

One of the failure process is Mode II cracks initiating within adiabatic shear bands (ASB) occurring around the circumference of the impact face. This failure process has been used to predict penetration performances of kinetic penetrator made of uranium and tungsten alloys. This prediction originated from firing of these penetrator materials again conventional hard roll armour steel revealing chiselling originating from adiabatic shear bands, see Figure 1 [5]. Consequent laboratory testing has revealed that the penetration performance was found to increase with the decrease of the strain at initiation of the adiabatic shear band.

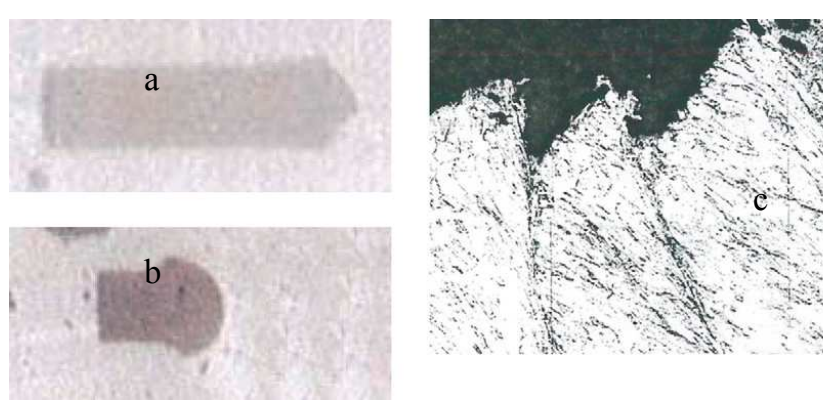

Fig. 1. Residual penetrator made of (a) U0.75Ti and (b) $90 \% \mathrm{~W}$ alloys. (c) Section of a residual penetrator made of $90 \% \mathrm{~W}$ alloy revealing multiple shear bands [5].
The second failure process observed is tensile cracking occurring in the center of the Taylor specimen, and sometimes at the circumference of the impact face. Tensile failure in the specimen center has been observed with highly ductile metals like nickel, aluminium alloy and copper [6,7], see Figure 2. For the nickel, a decrease of the hardness was measured near the tensile failure zone revealing that recrystallization occurred [7].

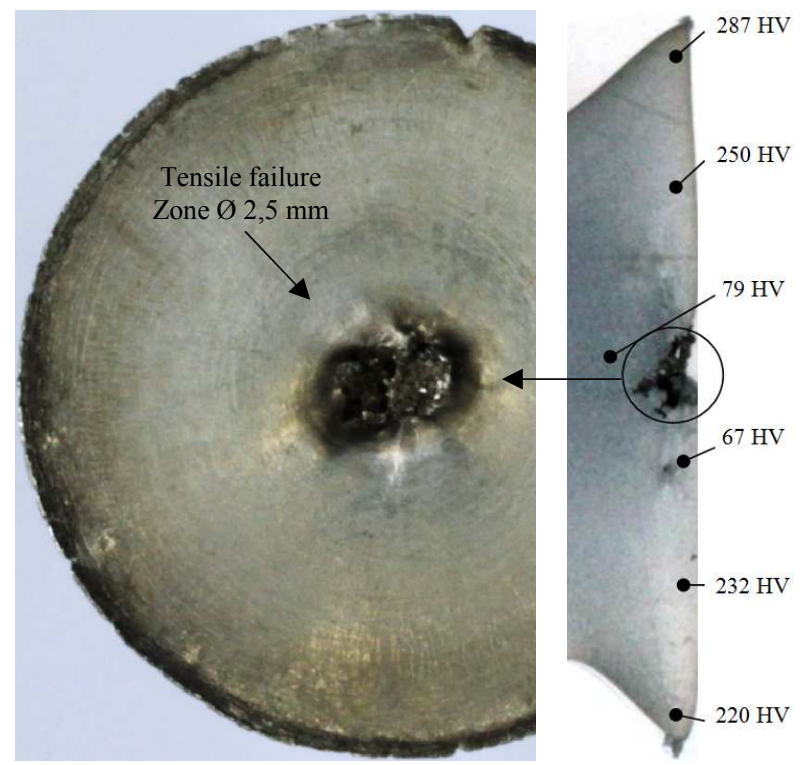

Fig.2. Tensile failure zone of a Taylor specimen made of nickel tested at $453 \mathrm{~m} / \mathrm{s}$ [7].

Taylor testing has been intensively used in the original configuration consisting of one cylindrical specimen impacting an anvil made of hard steel as to reproduce a rigid wall, referred as the single Taylor test. To simulate the single Taylor test it is required to make an estimation of the friction coefficient between the

\footnotetext{
* Corresponding author: h.couque@nexter-group.fr
} 
specimen and the anvil, as well as, to assume that the anvil is rigid. With the symmetric loading procedure introduced by Erlich et al. [8], such hypotheses are no longer needed. In addition, friction occurring with the single configuration has been found to delay adiabatic shear band formation when compared to the symmetric configuration [9]. Such results motivate the use of the symmetric Taylor test configuration to study the failure processes involved in the impact Taylor specimen.

Numerical simulations of the symmetric Taylor test have been conducted with the hydrocode AUTODYN as to reproduce the failure processes observed with a highly ductile nickel and a high strength tungsten alloy. Because the adiabatic shear failure process is occurring along a three dimension path, the 3D module of AUTODYN was used. Failure criteria such as tensile and shear effective plastic strain have been evaluated to reproduce the failure mechanisms of the Taylor specimen.

\section{The symmetric Taylor test}

When compared to single Taylor testing, symmetric Taylor testing involves one cylindrical specimen sent with a gas gun against another identical specimen located at the gun muzzle. For the symmetric Taylor test, it is equivalent either to send two specimens against each other at a given impact speed $V_{i}$ or to send one specimen at a speed $2 V_{i}$ against a second specimen at rest.

One inconvenient of Erlich's approach is the use of ceramic pins to locate the specimen sitting at the gun muzzle making difficult coaxial and planar impact of the two specimens. To facilitate planar and coaxial impacts, two testing procedures involving Teflon sabots have been developed by the author [10]. The first procedure addresses materials of strength greater than $800 \mathrm{MPa}$ in which the Teflon sabots are deformed with the Taylor specimens. The second procedure was developed for low strength materials, $100-800 \mathrm{MPa}$, in which a Teflon sabot and Teflon supports were designed to not interfere with the Taylor specimens.

The first procedure was used for a high strength tungsten alloy, $1500 \mathrm{MPa}$ in yield stress. The second procedure was used for the low strength pure nickel, 240 $\mathrm{MPa}$ in yield stress.

\subsection{Experimental procedure for pure nickel}

A nickel elaborated by Eramet in plate $12 \mathrm{~mm}$ thick by electrodeposition with a $99,99 \%$ content of nickel was employed. The nickel was used in a heat treated condition providing a quasi-static yield stress of $240 \mathrm{MPa}$ [6].

The experimental set-up is shown in Figure 3 with two Taylor specimens $9 \mathrm{~mm}$ in diameter and $36 \mathrm{~mm}$ in length. The loading system consist of a $25 \mathrm{~mm}$ caliber gas gun launching one Taylor specimen guided with a Teflon sabot which is arrested prior impact using copper inserts. The velocity of the launched specimen was measured using two laser beams separated by $18 \mathrm{~mm}$ located $30 \mathrm{~mm}$ behind the impact plane. The Taylor specimen located at the gun muzzle is positioned with two crushable Teflon supports. X ray observations were conducted with a Teflon witness bar in contact with the second Teflon support as to verify that the Teflon supports of the impacted Taylor specimen did not move prior impact [8].

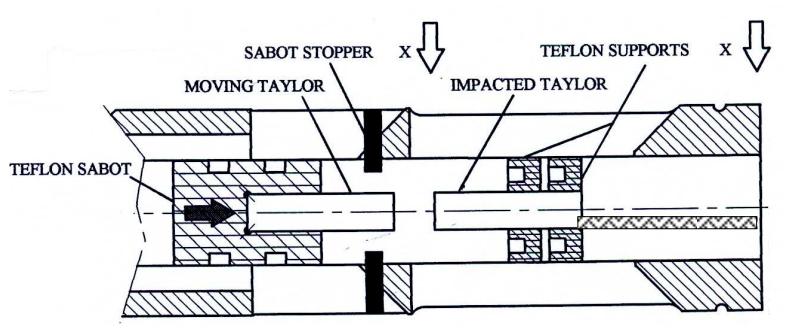

Fig. 3. Schematic of the symmetric Taylor test for low strength materials.

A numerical investigation has been conducted to establish that the Teflon supports did not interfere during the plastic deformation of Taylor specimens made of aluminium for a test conducted at an impact speed of 335 $\mathrm{m} / \mathrm{s}[8]$.

\subsection{Experimental procedure for tungsten alloy}

A tungsten alloy was elaborated in bar $12 \mathrm{~mm}$ in diameter by Cime Bocuze by powder metallurgy. The process involved a sintering cycle followed by swaging and a heat treatment as top reach a yield stress of $1500 \mathrm{MPa}$.

The experiment set-up is shown in Figure 4 with two Taylor specimens $9 \mathrm{~mm}$ in diameter and $36 \mathrm{~mm}$ in length. The loading procedure is similar at the precedent at an exception that the two sabots are identical and the launched sabot is not arrested. The sabots remain in contact during the deformation of the Taylor specimens. Through numerical simulations, it has been verified that the low amplitude of the reflected stress waves originating from the Teflon sabots did not add any plastic deformation to the Taylor specimens [8].

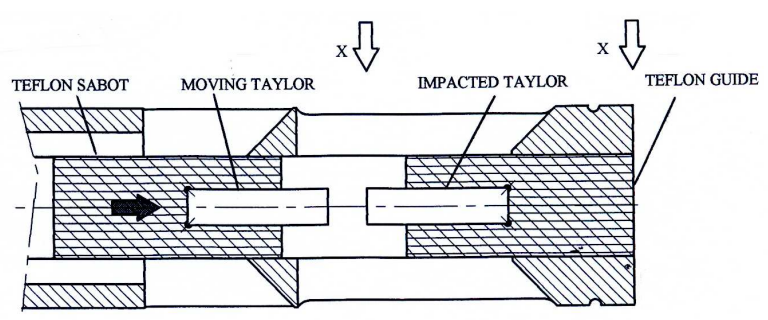

Fig. 4. Schematic of the symmetric Taylor test for high strength materials.

\subsection{Experimental results}

Figure 5 shows Taylor specimens tested at different impact speed. Mode II cracks were found to be generated at a threshold impact speed, $\mathrm{V}_{\mathrm{T}}$, of $250 \mathrm{~m} / \mathrm{s}$ for Taylor specimens made of tungsten alloy, see Figure 6. Mode II cracks were estimated to initiate at an impact speed of $453 \mathrm{~m} / \mathrm{s}$ for Taylor specimens made of pure nickel, see Figure 5. No tensile cracks were observed with the tungsten alloy specimens. In the contrary, tensile cracks 
in the center of the specimen, recall Figure 2, was observed with the nickel tested at $453 \mathrm{~m} / \mathrm{s}$.

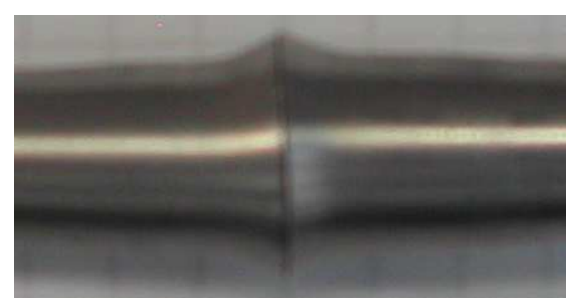

Nickel

$\mathrm{V}_{\mathrm{i}}=340 \mathrm{~m} / \mathrm{s}$

No ASB

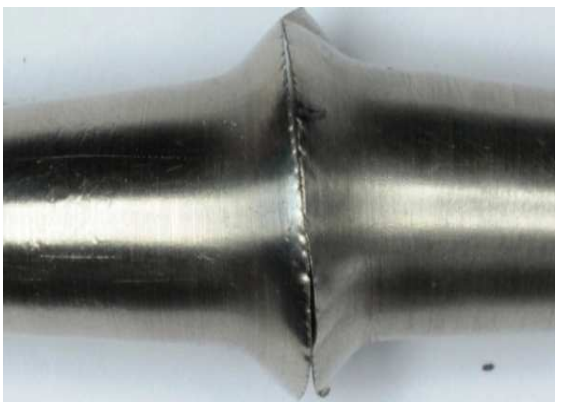

Nickel

$\mathrm{V}_{\mathrm{i}}=453 \mathrm{~m} / \mathrm{s}$

ASB

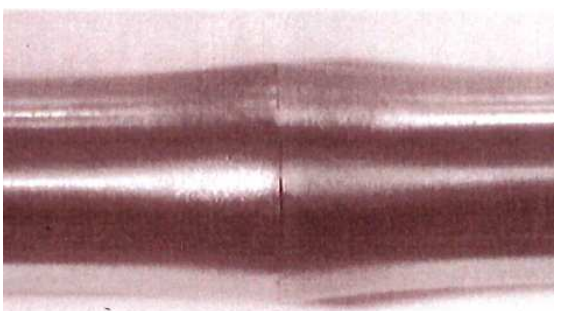

W alloy

$\mathrm{V}_{\mathrm{i}}=207 \mathrm{~m} / \mathrm{s}$

No ASB

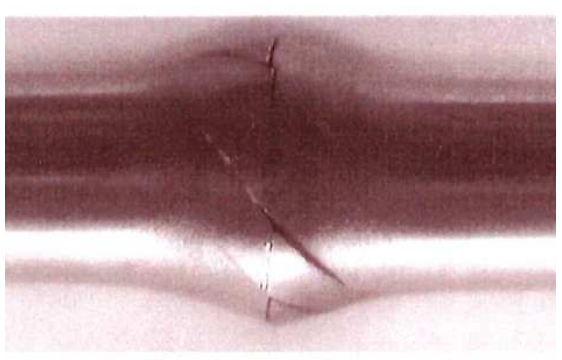

W alloy

$\mathrm{V}_{\mathrm{i}}=301 \mathrm{~m} / \mathrm{s}$

ASB

Fig. 5. Symmetric Taylor specimens made of nickel and tungsten alloy.

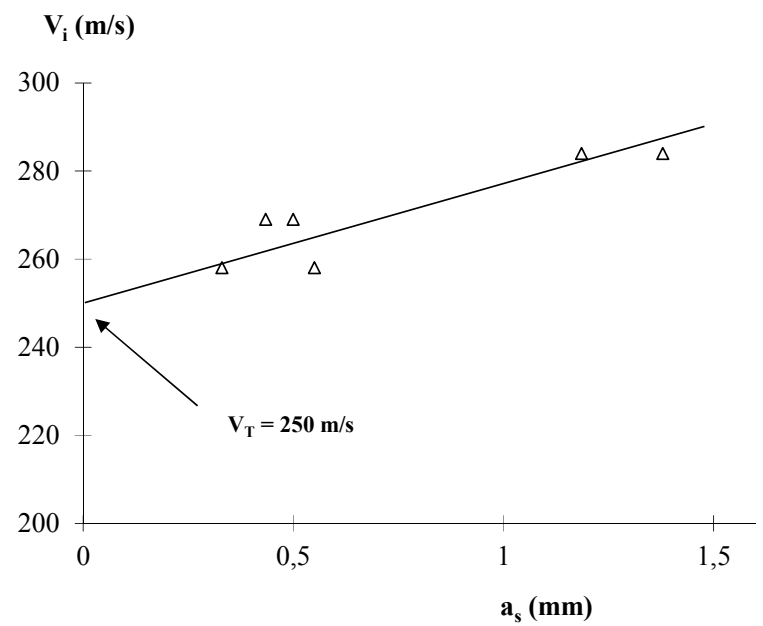

Fig. 6. Impact velocity, $\mathrm{V}_{\mathrm{i}}$, function of the average shear crack length, $a_{s}$, for Taylor specimens made of the high strength tungsten alloy.

\section{Numerical simulation procedures}

Numerical simulations were conducted with the Lagrange processor of the finite-difference finite element hydrocode AUTODYN. Simulations of the Taylor test were conducted with a numerical model reproducing the specimens, the sabots and the gun. The mesh of the Taylor specimens is composed of cells $200 \mu \mathrm{m}$ in size.

High strain rate and temperature dependences along with the strengthening occurring in the viscous regime were taken in account using a modified Johnson-Cook model (JCM) [11].

The modified Johnson-Cook model includes a power strain rate component added to the logarithm strain rate term of the original Johnson-Cook (JC) formulation, $D(\dot{\varepsilon}$ / $\left.\dot{\varepsilon}_{1}\right)^{k}$, with $D$ and $k$ two constants. This component is normalized by a reference strain rate, $\varepsilon_{l}$, equal to $10^{3} \mathrm{~s}^{-1}$ delimitating the thermally activated regime and the viscous regime. The equivalent stress function of plastic strain, $\varepsilon_{p}$, strain rate, $\dot{\varepsilon}$, and temperature, $T$, is expressed as :

$\sigma=\left(A+B \varepsilon_{p}^{n}\right)\left(1+C \ln \left(\dot{\varepsilon} / \dot{\varepsilon}_{o}\right)+D\left(\hat{\varepsilon} / \hat{\varepsilon}_{l}\right)^{k}\right)\left(1-\left[\left(T-T_{r}\right) /\left(T_{m}-T_{r}\right)\right]^{m}\right)$

with the usual constants of the classical Johnson-Cook formulation: $T_{r}, T_{m}$ the room and melting temperatures, $\dot{\varepsilon}_{o}$, a reference strain rate equal to $1 \mathrm{~s}^{-1}$ and $A, B, C, n, m$ five material constants describing the mechanical response. This formulation enables to go back to the classical Johnson-Cook formulation when strain rates are lower than $10^{3} \mathrm{~s}^{-1}$. The constants for the nickel and the tungsten alloy are provided in Table 1.

A saturation stress in the $10^{4} \mathrm{~s}^{-1}$ strain rate regime was introduced based on Steinberg's argument which stipulates that at a given strain rate all effects of strain rate have saturated and the material strength becomes independent of strain rate [9]. Strength levelling observed at high impact speeds with the direct impact Hopkinson pressure bar technique has motivated the choice of a strain rate threshold, $\dot{\varepsilon}_{T H}$, of $20000 \mathrm{~s}^{-1}$ [11].

Table 1. Modified Johnson-Cook constants.

\begin{tabular}{|c|c|c|c|c|c|c|c|}
\hline Material & $\begin{array}{c}\mathrm{A} \\
(\mathrm{MPa})\end{array}$ & $\begin{array}{c}\mathrm{B} \\
(\mathrm{MPa})\end{array}$ & $\mathrm{C}$ & $\mathrm{n}$ & $\mathrm{m}$ & $\mathrm{D}$ & $\mathrm{k}$ \\
\hline Nickel & 200 & 800 & 0.01 & 0.5 & 0.3 & 0.25 & 0.6 \\
\hline W alloy & 1750 & 829 & 0,001 & 0.6 & 1.1 & 0,0015 & 2.3 \\
\hline
\end{tabular}

\section{Results}

The 3D numerical model used is shown in Figure 7a along with material targets located in the plastically deformed region of the Taylor specimens. Simulations were conducted at impact speed of $543 \mathrm{~m} / \mathrm{s}$ and $250 \mathrm{~m} / \mathrm{s}$ for the pure nickel and the tungsten alloy, respectively. The loading duration was found to be $60 \mu$ s for the pure nickel and $30 \mu$ s for the tungsten alloy as shown in Figure $7 \mathrm{~b}$ with the history of the material targets. 
(a)

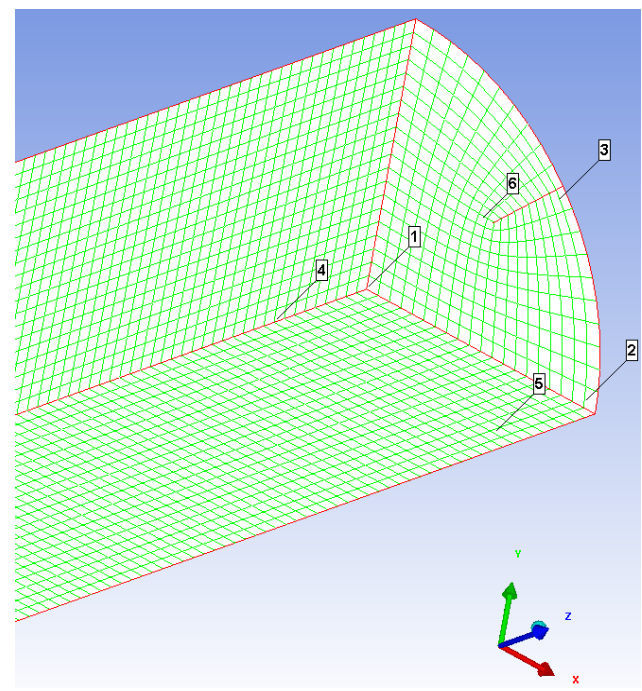

(b1) Nickel $453 \mathrm{~m} / \mathrm{s}$
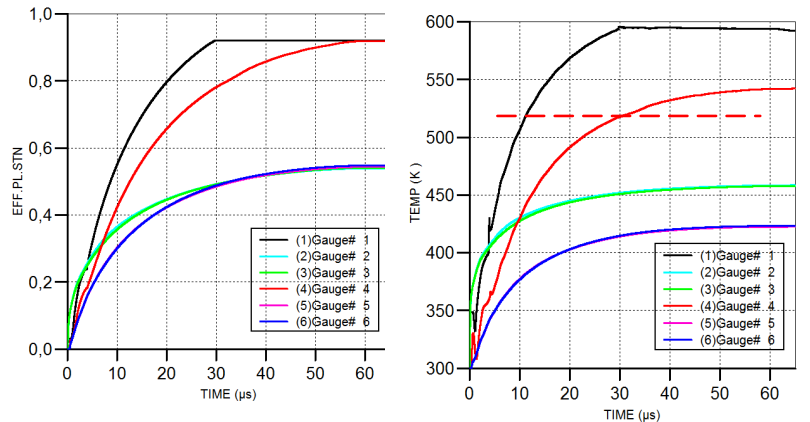

(b2) Tungsten alloy $250 \mathrm{~m} / \mathrm{s}$
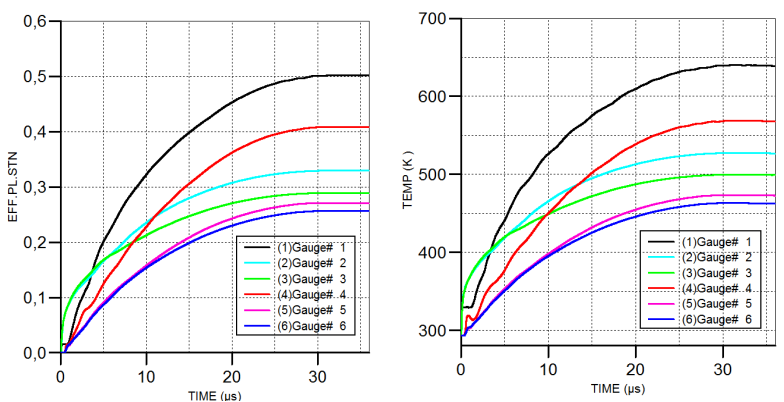

Fig. 7. $3 \mathrm{D}$ numerical model (a). Plastic deformation and temperature histories of the targets 1 to 6 for the nickel tested at $453 \mathrm{~m} / \mathrm{s}$ (b1) and the tungsten alloy tested at $250 \mathrm{~m} / \mathrm{s}$ (b2). Nickel recrystallization temperature is indicated by a dot line.

\section{4-1 Tensile failure of the nickel specimen}

The decrease in strength associated with the recrystallization phenomena was taken in account in the numerical simulation by introducing a recrystallization temperature criterion. The work of Lichtenberger provides recrystallized hardness temperature curves for different level of initial plastic deformation [11]. From these curves, quasi-static recrystallization temperatures of 290 and $230{ }^{\circ} \mathrm{C}$ were deduced for a plastic deformation of 30 and $70 \%$, respectively. Based on this work, a temperature of $230{ }^{\circ} \mathrm{C}$ was selected as a recrystallization temperature criterion. Such temperature is reached $12 \mu \mathrm{s}$ after impact, see Figure 7 [7]. At this instant the plastic deformation is about $70 \%$.
Numerical simulations were consequently generated incorporated two types of JCM models, with the first model representative of the original material, see section 3.1 , and the second model representative of the recrystallized material. The yield and hardening coefficients for the recrystallized material were identified as to provide a rigid plastic behaviour with a quasi-static yield stress of $50 \mathrm{MPa}$. Precisely, the A and B coefficients of the JCM models were 200 and $800 \mathrm{MPa}$ for the first model, and 100 and $400 \mathrm{MPa}$ for the second model, respectively. The simulations were conducted by monitoring the temperature. At the recrystallization temperature criterion of $230^{\circ} \mathrm{C}$, the model representative of the recrystallized material was applied.

An effective tensile failure criterion of 0,8 was identified to reprodurce the planar size, Recall Figure 2. The failure zone was not quite reproduce in depth as it was limitated to an axial tensile failure of $1 \mathrm{~mm}$, see Figure 8. Based on the work of Chapman and all, the extend of tensile failure inside the specimen comes from the coalescence of radial release waves at the specimen axis [10]. As suggested in this work, simulations conducted with a critical treshold pressure appear to be a mean to generate this bulk tensile failure.

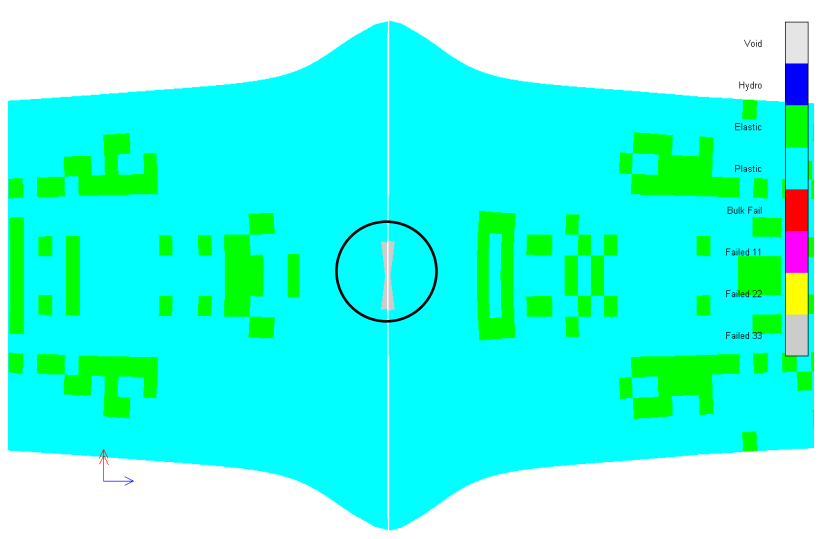

Fig. 8. Tensile failure zone for the nickel tested at $453 \mathrm{~m} / \mathrm{s}$.

\section{4-2 Shear failure of the nickel and tungsten alloy specimens}

The shear failure process was reproduced using an effective shear strain criterion for the two metals.

Figures 9 reveals the shear failure zones obtained with a criterion $\varepsilon_{12}=\varepsilon_{23}=\varepsilon_{31}$ of 0,10 and 0,12 , for the nickel tested at $453 \mathrm{~m} / \mathrm{s}$. Figures 10 reveals the shear failure zones obtained with a criterion $\varepsilon_{12}=\varepsilon_{23}=\varepsilon_{31}$ of 0,55 and 0,57 , for the tungsten alloy at an impact speed of 250 $\mathrm{m} / \mathrm{s}$.

The use of a shear strain criterion enables to reproduce the shear failure processes observed with Taylor specimens made of a pure nickel and of a high strength tungsten alloy. To obtain a finer resolution, it will be necessary to refine the mesh size and to conduct a convergence study with meshes $25,50,75$ et $100 \mu \mathrm{m}$ in size. 
(a)

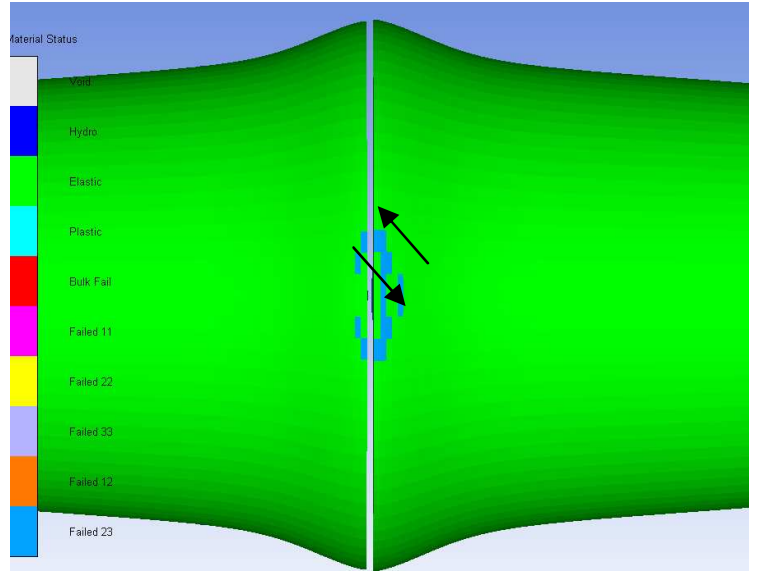

(b)

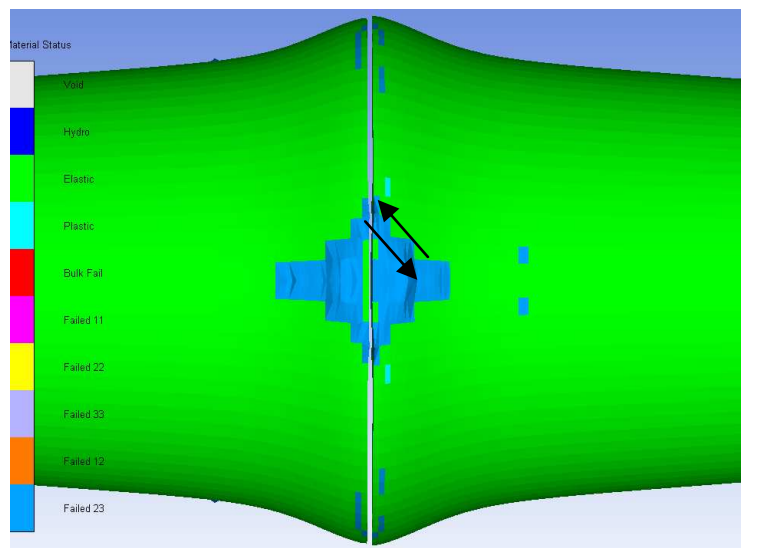

Fig. 9. Shear failure for the nickel at an impact speed of 453 $\mathrm{m} / \mathrm{s}$. Shear criterion $\varepsilon_{12}=\varepsilon_{23}=\varepsilon_{31}=0,10$ (a) $=0,12$ (b).

(a)

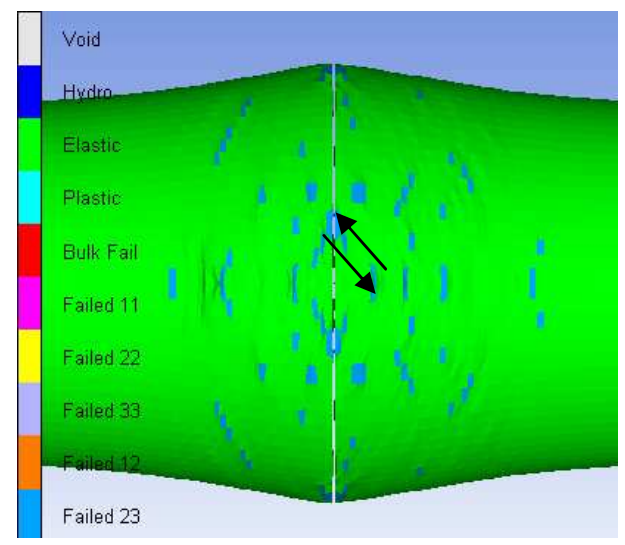

(b)

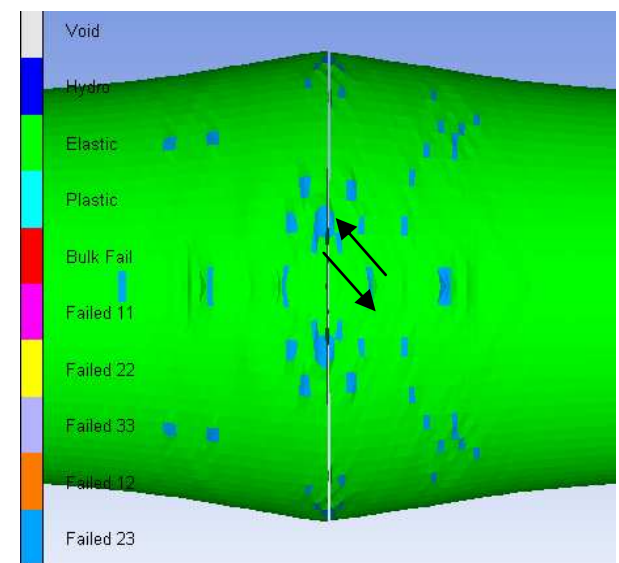

Fig. 10. Shear failure for the tungsten alloy at an impact speed of $250 \mathrm{~m} / \mathrm{s}$. Shear criterion $\varepsilon_{12}=\varepsilon_{23}=\varepsilon_{31}=0,55$ (a) $=0,57$ (b).

\section{Conclusion}

Experimental and 3D numerical investigations were conducted to evaluate the failure processes of impact Taylor specimens made of a pure nickel and a high strength tungsten alloy. The symmetric loading procedure of the Taylor test was used to provide frictionless conditions at the impact interfaces.

Because recrystallization occurring in the center of the nickel specimen results in a softening state, the numerical simulations involved two materials models one representing the initial state and an another one modelling the softening state. Tensile failure occurring in the center of the specimen was triggered through the use of an effective tensile strain criterion. Shear cracks on the periphery of the Taylor specimens originating from adiabatic shear bands were modelled with the use of an effective shear strain criterion.

For the tungsten alloys, no tensile failure was observed as well as any evidence of recrystallization of the highly ductile nickel phase was identified. The only failure process observed with the tungsten alloy consisting of shear cracks initiating through adiabatic shear bands was modelled with the use of an effective shear strain offset.

This research was in part sponsored by the Direction Générale de l'Armement.

\section{References}

1. Taylor G. I., Proc. Roy. Soc. London A 194, pp. 289299 (1948)

2. D. C. Erlich, P. Chartagnac, J. Phys. C5, pp. 455-462 (1985)

3. T. J. Holmquist, G. R. Johnson, J. Phys. IV France C3-1, pp. 853-860 (2006)

4. H. Couque, G. Nicolas, C. Altmayer, Int. J. Imp. Eng. 34, pp. 412-423 (2007)

5. Adiabatic Shear Localization - Frontier and Advances, Edited by B. Dodds and Y. Bai, Elsevier Ltd (2012)

6. D. J. Chapman, D. D. Radford, M. Reynolds, P. D. Church, Inter. J. Fract. 134, pp. 41-57 (2005)

7. H. Couque, Europ. Phys. J. - Web of Conf. 94, pp. 1$5(2015)$

8. D. C. Erlich, D. Shockey, L. Seaman, Conf. Shock Waves Condensed Matter, Eds Amer. Inst. Phys. 402-406 (1982)

9. H. Couque, A. Lichtenberger, E. Lach, B. Salesse, J. Phys. IV France 10, pp. 353-358 (2000)

10. H. Couque, J. Phys. IV France 10, pp. 179-184 (2000)

11. H. Couque, R. Boulanger, F. Bornet, J. Phys. IV France 134, pp. 87-93 (2006)

12. D. Steinberg, S. Cochran S. G., M. Guinan, J. Appl. Phys. 561, 1498 (1980)

13. A. Lichtenbeger, ISL Technical Report «Etude du cuivre et du nickel pour revêtements de charges creuses mise en forme par matriçage », S-R 902/90 (1990) 
